auseinander gerissen habe, was sodann ein Schwinden der Leuchtkraft zur Folge hatte. Dieser letztere Process schritt von oben nach unten vor.

Die Erscheinung war eine offenbar eruptive, fällt auch in die Fleckenzone; allein sie lässt sich mit keinem Gebilde in der Photosphäre in Verbindung bringen; es war auch die auf allen Fleckengebieten am Rande sonst auftretende rothe Linie $667 \%$ an dieser Stelle nicht zu sehen; vielleicht lag der Fusspunkt des Gebildes etwas entfernt vom Rande.

Kalocsa 1895 Januar.

F. Fényi, S. J.

\title{
Filar Micrometer Measures of Nova Aurigae in 1894
}

\author{
made with the 36 in. Equatorial of the Lick Observatory.
}

In A. N. 3143 and 3238 , I have given my measures of the position of Nova Aurigae $(A)$ with reference to two stars $(E$ and $F$ ) near it.

Mr. Burnham had previously measured the same stars (M. N. Vol. LII) and my work has been done in hopes of detecting motion or parallax in the Nova. But neither of these has been detected.

During 1894 I have secured three nights' further observation of these three objects. They are as follows.

$A$ and $E$.

\begin{tabular}{|c|c|c|c|}
\hline I 894.867 & $323 \div 5$ & $74: 5^{2}$ & Nov. I 2 \\
\hline .884 & 323.5 & 74.70 & Nov. 18 \\
\hline 1895.002 & $3^{2} 3 \cdot 3$ & 74.75 & Dec. $3 I$ \\
\hline \multirow[t]{2}{*}{1894.918} & 323.43 & 74.66 & \\
\hline & $A$ and & $F$ & \\
\hline 1894.867 & 32.6 & 85.09 & Nov. I 2 \\
\hline .884 & $3^{2.8}$ & 84.74 & Nov. 18 \\
\hline 1895.002 & 32.5 & 84.99 & Dec. $\mathbf{3}^{\mathbf{I}}$ \\
\hline 1894.918 & $3^{2.63}$ & 84.94 & \\
\hline
\end{tabular}

Taking the yearly means of my measures, for the season of observation, we have:

$$
A \text { and } E \text {. }
$$

\begin{tabular}{|c|c|c|c|}
\hline 1892.860 & $3^{2} 3 \cdot 3^{8}$ & 74.580 & (16 nights) \\
\hline 1893.905 & $3^{2} 3.43$ & 74.506 & (1 4.13 nights) \\
\hline I 894.9 I 8 & $3^{2} 3.4 \mathrm{I}$ & 74.657 & (3 nights) \\
\hline \multicolumn{4}{|c|}{$A$ and $F$} \\
\hline I & $3^{2.63}$ & $84.93^{6}$ & (1 8 nights) \\
\hline & 32.89 & 84.909 & (8 nights) \\
\hline 1894.918 & 3263 & 84.940 & (3 nights) \\
\hline
\end{tabular}

If we compare these yearly observations with their means we get:

$A$ and $E$.

\begin{tabular}{l|l|l}
1892 & +0.027 & +0.001 \\
1893 & -0.023 & +0.075 \\
1894 & -0.004 & -0.076 \\
& $A$ and $F$. \\
1892 & +0.087 & -0.008 \\
1893 & -0.173 & +0.019 \\
1894 & +0.087 & -0.012
\end{tabular}

These shew conclusively there has been no percep. tible motion in the Nova, nor in either of the other stars, during my two years' observations. This is all the more surprising because spectroscopic observations seem to have shown enormous motion in the Nova in the line of sight.

I cannot account for the difference of nearly $0: 2$ during 1893 in the position angle of $A F$. The observations of that year seemed to show a real change in this angle, but those of 1894 negative any change.

Mr. Burnham's observations referred to are :

$$
A \text { and } E \text {. }
$$

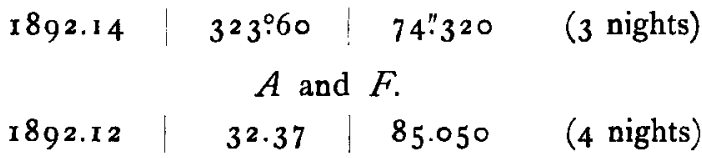

I have carried the decimals out one place further for the sake of comparison.

These differ from the yearly means of my measures by the following quantities:

$$
\begin{gathered}
A \text { and } E . \\
-0.19 \text { +0.261 } \\
A \text { and } F . \\
+0.24 \quad-0.122
\end{gathered}
$$

These differences are doubtless due to personal equation. Considering however the distances measured, and the nature of the Nova and the faintness of $E$, they are by no means excessive.

The physical appearance of the Nova does not seem to have changed any since 1893 .

At the last observation in 1894 with a power of 350 , I compared it carefully with $F$. The seeing was bad and it gave images very much alike to both objects. The Nova was possibly a tenth of a magnitude less than $F$ though this was not certain - the two looked so much alike.

The resulting magnitude - on the scale used by Mr. Burnham in his double star measures - would be 10.5 .

$I$ also saw it with the $r 2$ inch early in the summer, when it was first visible in the early dawn, and there seemed then to be essentially no difference between the Nova and $F$.

Mt. Hamilton, 1895 Jan. I.

\section{E. E. Barnard.}

Note: In my paper on Nova Aurigae in A.N. $323^{8}$ p. $385,1^{\text {th }}$ line from bottom of page, for o". 30 read o."22. E. E. B. 